\title{
Correlating Mechanical Properties and Anti-Wear Performance of Tribofilms Formed by Ionic Liquids, ZDDP and Their Combinations
}

\author{
Alexander K Landauer ${ }^{1}$, William C. Barnhill, Jun $\mathrm{Qu}^{*}$ \\ Materials Science and Technology Division, Oak Ridge National Laboratory, Oak Ridge, TN \\ 37830, USA
}

\begin{abstract}
This article examines the elasticity, hardness, and resistance-to-plastic-deformation $\left(P / S^{2}\right)$ measured via nanoindentation of several tribofilms and correlates these properties to friction and wear behavior. The tribofilms were generated by oil ball-on-plate sliding lubricated by a base oil containing an ionic liquid, phosphonium-organophosphate or ammonium-organophosphate, zinc dialkyldithiophosphate (ZDDP), or combinations of IL and ZDDP. Nanoindentation was conducted at room and elevated temperatures. While there seems little correlation between the tribofilm hardness and friction or wear behavior, a higher modulus generally leads to better friction or wear performance. In contrast, a lower $P / S^{2}$ ratio tends to reduce friction and improve wear protection, which is in an opposite trend as reported for bulk materials. This is likely attributable to the dynamic self-healing characteristics of tribofilms.
\end{abstract}

Keywords: Nanoindentation, Ionic liquid, ZDDP, Tribofilm, Hardness, Modulus, Resistance-toplastic-deformation

${ }^{1}$ Present: School of Engineering, Brown University, Providence, RI 02912, USA

*Corresponding author, qujn@ ornl.gov 


\section{Introduction}

Friction and wear are deleterious factors influencing the efficiency and durability of mechanical systems, e.g. internal combustion engines, where frictional losses account for $10 \%$ to $15 \%$ of the energy of combustion [1]. Oil additives are used to minimize energy loss and promote system longevity. The most common anti-wear additive for commercial engine oils is zinc-dialkyl-dithiophosphate (ZDDP) [2].

Room temperature ionic liquids (ILs) have been explored for lubrication since 2001 [3]. Ionic liquids are typically large salts with diffuse charge and tailorable properties that resist crystallization at low temperatures [4]. Recent advances show that some oil-miscible ILs possess strong friction and wear reduction characteristics [5-11] as lubricant additives, and the most recent research revealed an interesting synergism between phosphonium-alkylphosphate ILs and ZDDP in friction and wear control [12-14], resulting in improved engine efficiency when formulated into a low-viscosity engine oil [14]. It is known that both IL and ZDDP lubricants form a protective tribofilm on contact areas, and the composition and mechanical properties of the tribofilm depend on the materials of the friction faces, the base lubricant, and additives [15]. Although a number of investigations in the literature explore the nanostructure and chemical composition of the tribofilms formed by ILs [4-14, 16-21] and IL+ZDDP combinations [13], the understanding of mechanical properties of the tribofilms and their relations to the friction and wear performance is limited [13]. In this study, we characterize selected IL and IL+ZDDP tribofilms using nanoindentation to measure elasticity, hardness, and the hardness to stiffness squared ratio $\left(P / S^{2}\right)$ at both room and elevated temperatures. The mechanical properties of the tribofilms are correlated to the tribological behavior to gain fundamental insights into the friction and wear reduction mechanism of the IL-additized lubricants. 


\section{Material and Methods}

\subsection{Tribofilm Generation}

Seven lubricants were prepared each using Shell XHVI 4 cSt base oil provided by Shell Global Solutions (Houston, TX) as base stock. The additives consisted of single ILs, ZDDP, or combined ZDDP and IL. Three oil-miscible ILs were used: trihexyltetradecylphosphonium bis(2-ethylhexyl) phosphate $\left(P_{66614}\right)$, tetraoctylphosphonium bis(2-ethylhexyl) phosphate $\left(P_{8888}\right)$ and trioctylammonium bis(2-ethylhexyl) phosphate $\left(N_{888} H\right)$. They were prepared at Oak Ridge National Laboratory following synthesis procedures described in past work [5, 11, 22]. A secondary ZDDP with oil solubility of 1-2 wt.\% was supplied by Lubrizol (Wickliffe, OH). All additives contained phosphorous, and thus each lubricant was blended adhering to International Lubricants Standardization and Approval Committee GF-5 specifications of 800 ppm maximum P concentration, resulting in IL treat rates of $1.04 \%$ for $P_{66614}$ and $P_{8888}$, and $1.74 \%$ for $N_{888} H$. IL+ZDDP combinations were blended such that IL and ZDDP each provided $400 \mathrm{ppm}$ of $\mathrm{P}$, for treat rates of $0.52 \% P_{66614} / P_{8888}+0.4 \%$ ZDDP or $0.87 \% N_{888} H+0.4 \%$ ZDDP.

A tribological bench test was conducted for each lubricant under boundary lubrication (Plint TE77, Phoenix Tribology Ltd., Hampshire, UK). The instrument moved with linear periodic motion against a stationary specimen submerged in lubricant. A ball-on-flat geometry was used, with a $10 \mathrm{~mm}$ diameter AISI 52100 steel sphere sliding against a CL 35 gray cast iron flat. Test conditions were set to, $100^{\circ} \mathrm{C}$ surface temperature, normal load $100 \mathrm{~N}$, reciprocating frequency $10 \mathrm{~Hz}$, oscillation stroke $10 \mathrm{~mm}$, and sliding distance of $1000 \mathrm{~m}$. After testing, worn surfaces were cleaned with isopropanol. 


\subsection{Nanoindentation}

In the literature, nanoindentation has been used to characterize ZDDP tribofilms [23-28]. Our analysis employs the technique of Oliver and Pharr [25, 29]. Among the models for film indentation available, (e.g. [28, 30-32]), two ([30, 32]) techniques were implemented. Since wear tracks are rough and of non-uniform thickness the correction methods (designed for regular films) were contradictory and strongly correlated to the Oliver and Pharr results, and were thus discarded in the final analysis.

A parameter related to wear protection of coatings, the ratio of $P / S^{2}$ was introduced in [33, 34]. This parameter is closely associated to the plasticity index $(\psi)$ measure of the elastic-plastic balance of deformation, differing by a multiplicative factor of the inverse reduced elastic modulus and by topographical parameters [35]. Thus, a low value of $P / S^{2}$ indicates a high proportion of elasticity in the total elastoplastic response during indentation $[33,35]$. The ratio of hardness to modulus $(\mathrm{H} / \mathrm{E})$ is related to $P / S^{2}$ in a similar way as is $\psi$, and is used to assess elastic strain to failure during abrasive or erosive wear situation; however, H/E is less directly measurable in nanoindentation [36]. As such, $P / S^{2}$ provides relatively low-noise insight into the physical nature of the total deformation of the tribofilm.

In prior work, initial room-temperature nanoindentation results of the tribofilms generated by $P_{8888}$ and $P_{8888}+$ ZDDP were presented [13]. In this work, we expand the characterization effort to tribofilms of the three ILs described above and their combinations with ZDDP at room and, for a subset of films, at elevated temperatures.

Nanoindentation was conducted on a TI-950 TriboIndenter with a NanoDMA I (Hysitron, Minneapolis, MN) transducer under load control with a diamond $\left(E_{t}=1140 G P a\right.$ and $\left.v_{t}=0.07\right)$ Berkovich tip. Nanoindenter calibration consisted of a 100-indent area function routine on fused- 
quartz. The load function was trapezoidal with peak load $1200 \mu N$ and a hold period of 10 seconds, although no viscous effects were observed in preliminary dynamic tests.

Forty-five or more indents were collected for each tribofilm. Indent regions were ascertained via optical microscopy and selected based on scanning probing microscopy results. The tribofilm precluded typical surface preparation. Five to 20 indents were targeted per region of interest. Figure 1A shows a representative region with indent targets marked. A post-indent scanning probing microscopy surface profile is shown in Figure 1B. A subset of these tests was repeated with good agreement on a second instrument (also TI-950) for three films with 25 indents per tribofilm for validation prior to elevated-temperature indentation.

Elevated temperature nanoindentation tests were conducted on $Z D D P, P_{8888}$ and $Z D D P+P_{8888}$ derived tribofilms at three temperatures: $100^{\circ} \mathrm{C}, 150^{\circ} \mathrm{C}$, and $193^{\circ} \mathrm{C}$, with approximately 25 indents per temperature. After temperature equilibration (with $2^{\circ} \mathrm{C}$ error tolerance) and thermal drift stabilization $\left(\right.$ to $\pm 0.1^{\circ} \mathrm{C}$ ) an indentation procedure identical to that described above was conducted. 


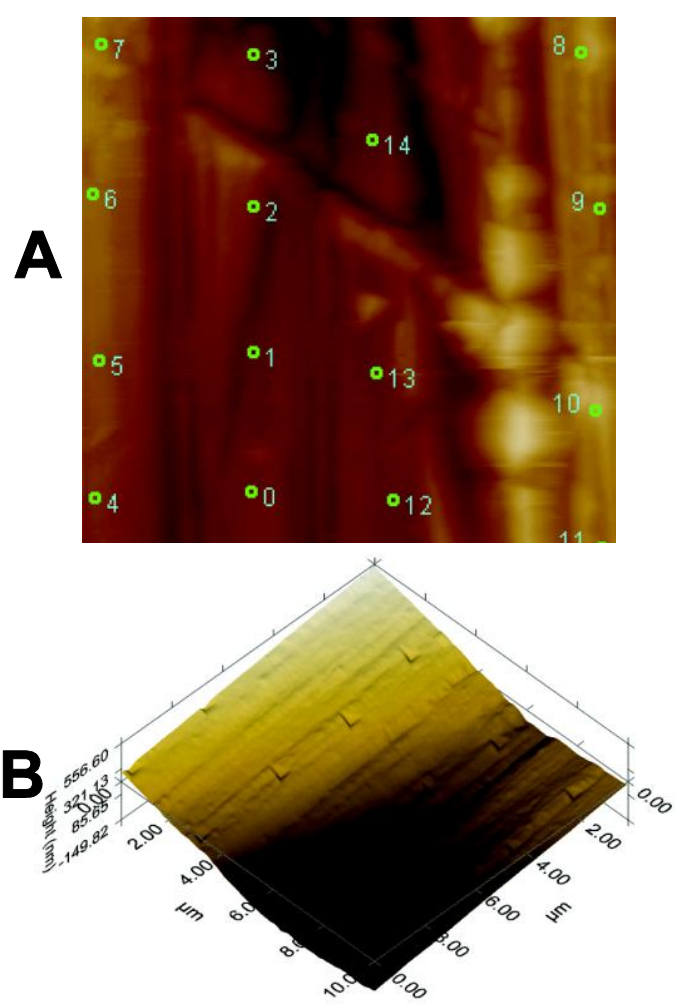

Figure 1. (A) Example scanning probing microscopy (SPM) image. (B) Post-indent SPM image of another tribofilm surface. The vertical scale is nanometers.

The control software (TriboScan, Hysitron) implemented the method of Oliver and Pharr to determine hardness and reduced modulus [29]. In this technique, hardness is the maximum normal load divided by maximum cross-sectional probe area at the specimen surface, i.e. $H=P / A$. The reduced modulus $\left(E_{r}\right)$ is $E r=(\pi / A)^{1 / 2}(S / 2)$, where $S$ is the slope of the unloading curve subsequent to peak load, and $\mathrm{A}$ is the probe area. The $P / S^{2}$ parameter was calculated with the same $S$ and load information from the instrument.

A correlation analysis determined parameters for the general linear model and identified extreme outliers. The normality (passed) and homoscedasticity (failed) were tested. An analysis of variance (ANOVA, $\alpha=0.01$, no assumption of equal variance) compared the reduced modulus, hardness, or the $P / S^{2}$ between the series of tribofilms. Games-Howell Pairwise Comparisons 
were made between the lubricant chemistries or testing temperatures to establish specific differences (Minitab 17, Minitab Inc, State College, PN).

\section{Results and Discussion}

\subsection{Tribological Results}

Table 1 summarizes the friction and wear results [13] in the tribological bench tests when the tribofilms were produced.

Table 1. Friction and wear summary for each lubricant [13].

\begin{tabular}{ccc} 
Lubricant & $\begin{array}{c}\text { Mean Friction } \\
\text { Coefficient (Last 50 m } \\
\text { of Sliding) }\end{array}$ & $\begin{array}{c}\text { Mean Flat Wear } \\
\text { Volume } \\
\mathrm{mm}^{3}\end{array}$ \\
\hline XHVI 4 + 0.8\% ZDDP & $0.115^{ \pm 0.001}$ & $0.138^{ \pm 0.047}$ \\
XHVI 4 + 1.04\% $P_{8888}$ & $0.116^{ \pm 0.003}$ & $0.105^{ \pm 0.010}$ \\
XHVI 4 + 1.04\% $P_{66614}$ & $0.111^{ \pm 0.003}$ & $0.179^{ \pm 0.045}$ \\
XHVI 4 + 1.74\% $N_{888 H}$ & $0.108^{ \pm 0.001}$ & $0.042^{ \pm 0.001}$ \\
XHVI 4 + 0.52\% $P_{8888}+0.4 \%$ ZDDP & $0.081^{ \pm 0.002}$ & $0.033^{ \pm 0.024}$ \\
XHVI 4 + 0.52\% $P_{66614}+0.4 \%$ ZDDP & $0.084^{ \pm 0.001}$ & $0.034^{ \pm 0.002}$ \\
XHVI 4 + 0.87\% $N_{888 H}+0.4 \%$ ZDDP & $0.115^{ \pm 0.001}$ & $0.065^{ \pm 0.010}$ \\
\hline
\end{tabular}

\subsection{Room Temperature Indentation}

Figure 2 graphically illustrates the relationships between friction coefficient, wear volume, and mechanical properties of corresponding tribofilms. Table 2 gives results for reduced modulus, $P / S^{2}$, and hardness with ANOVA post-hoc groupings. IL tribofilms generally have higher moduli and lower friction and wear compared to the ZDDP tribofilm. Typical indentation depths for tests range from $51.1 \pm 3.38 \mathrm{~nm}\left(\mathrm{P}_{66614}\right)$ to $93.4 \pm 4.72 \mathrm{~nm}($ ZDDP). The tribofilms generated with combined IL and ZDDP showed further improved friction and wear behavior along with higher moduli. Little correlation is apparent between wear and hardness. For the $P / S^{2}$ parameter two clusters appear, one with low $P / S^{2}$ and lower friction coefficient and wear volume, 
and the other with higher $P / S^{2}$ and greater friction coefficient and wear volume. This indicates $P / S^{2}$ as a candidate assessment of tribological performance for tribofilms rather than hardness.

Table 2. Summary of nanoindentation results. Sample size is after culling anomalous indents. Measurements are mean \pm standard deviation. Letters, e.g “(B)”, show the grouping results from an ANOVA with post-hoc comparison testing. A common grouping letter between any given measurements indicates no significant difference $(p<0.01)$.

\begin{tabular}{ccccc} 
Lubricant & $\mathrm{E}_{\mathrm{r}}$ & $\mathrm{H}$ & $\frac{P}{S^{2}}, \frac{n m^{2}}{\mu N}$ & $\begin{array}{c}\text { Sample } \\
\text { size } \\
\#\end{array}$ \\
\hline ZDDP [13] & $124^{ \pm 26.7}(\mathrm{C})$ & $5.1^{ \pm 1.41}(\mathrm{C})$ & $0.27^{ \pm 0.10}(\mathrm{AB})$ & 68 \\
$\mathrm{P}_{8888}[13]$ & $163^{ \pm 19.7}(\mathrm{~B})$ & $7.8^{ \pm 1.61}(\mathrm{AB})$ & $0.24^{ \pm 0.07}(\mathrm{~B})$ & 56 \\
$\mathrm{P}_{66614}$ & $154^{ \pm 16.2}(\mathrm{~B})$ & $8.5^{ \pm 1.52}(\mathrm{~A})$ & $0.28^{ \pm 0.04}(\mathrm{~A})$ & 96 \\
$\mathrm{~N}_{888} \mathrm{H}$ & $148^{ \pm 33.9}(\mathrm{~B})$ & $4.2^{ \pm 1.44}(\mathrm{D})$ & $0.16^{ \pm 0.07}(\mathrm{C}$ & 89 \\
$\mathrm{ZDDP}+\mathrm{P}_{8888}[13]$ & $171^{ \pm 42.4}(\mathrm{AB})$ & $6.5^{ \pm 2.94}(\mathrm{BC})$ & $0.17^{ \pm 0.05}(\mathrm{C})$ & 61 \\
$\mathrm{ZDDP}+\mathrm{P}_{66614}$ & $185^{ \pm 16.0}(\mathrm{~A})$ & $8.2^{ \pm 2.00}(\mathrm{AB})$ & $0.18^{ \pm 0.03}(\mathrm{C})$ & 45 \\
ZDDP+N & $186^{ \pm 28.0}(\mathrm{~A})$ & $7.3^{ \pm 2.06}(\mathrm{AB})$ & $0.17^{ \pm 0.04}(\mathrm{C})$ & 49 \\
\hline
\end{tabular}

The groupings in Table 2 suggest that higher modulus is associated with strong anti-wear performance. Hardness, a corollary to resistance to penetration, does not lead to coherent performance groupings by type. The $P / S^{2}$ parameter is a measure of resistance to plastic deformation [33]. Greater $P / S^{2}$ has been associated with great wear protection for bulk or coated materials $[33,34]$. For a bulk material or pre-deposited coating, plastic deformation causes permanent surface damage or material removal, and thus higher $P / S^{2}, \psi$, and $\mathrm{H} / \mathrm{E}$ are typically associated with higher wear resistance [36]. In contrast, these results support the explanation first outlined in Qu et al. 2015 [13] that follows from the description of tribofilms as in-situ formed, sacrificial, and self-healing systems [7, 13, 17, 39]. In this paradigm, elasto-plastic deformation, more often occurring at 'tall' surface asperities, acts to smoothen the contact area. Lower $P / S^{2}$ may be beneficial since a more compliant tribofilm reduces shear resistance (lower friction) and the self-smoothening effect reduces the asperity collision severity (lower wear). 

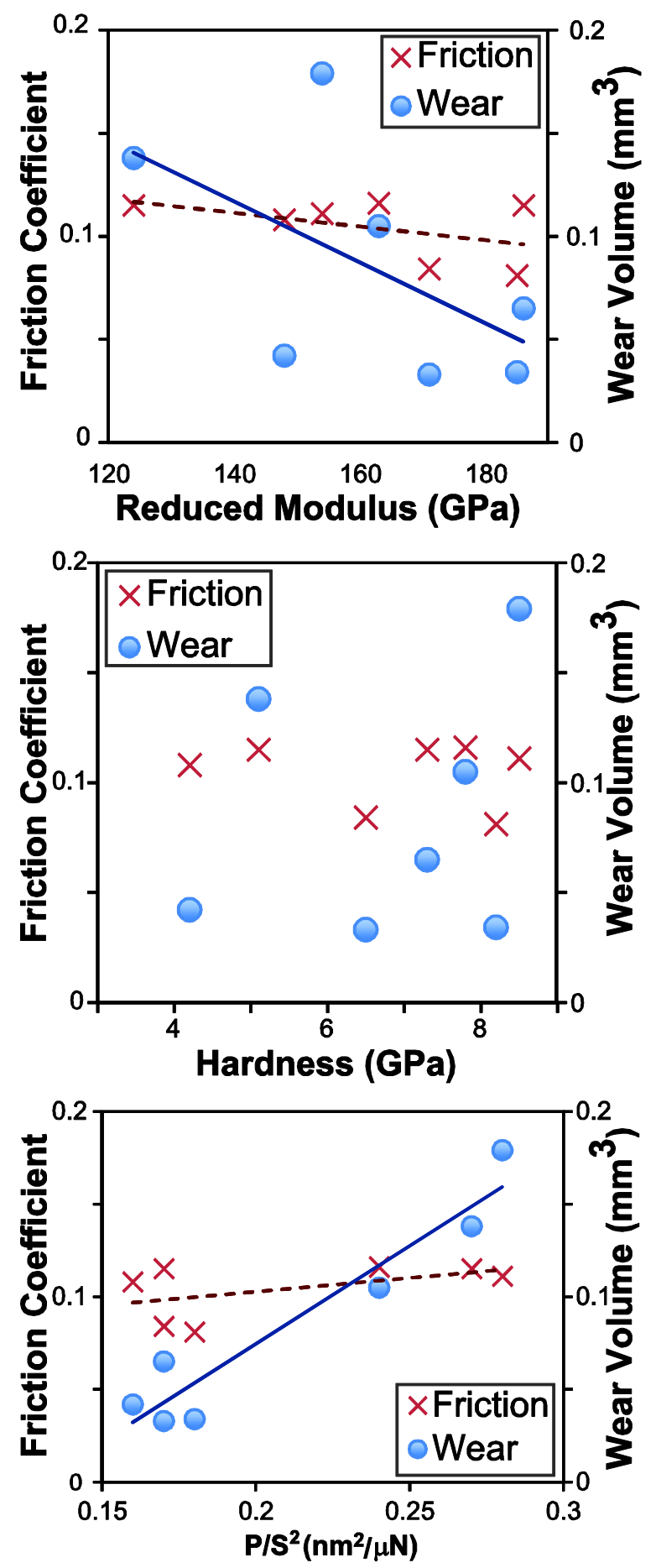

Figure 2. Friction coefficient and wear volume for each tribofilm and measured material property. Low friction and wear volume is good. Error bars have been omitted for visual clarity, see Tables 1 and 2 for descriptive statistics. 


\subsection{High Temperature Nanoindentation}

The effect of elevated temperature on the subset of tribofilms is shown in Figure 3. The ZDDP tribofilm exhibited some temperature dependence. Reduced modulus and hardness behaved similarly, but with a greater than $20 \%$ increase from $25^{\circ} \mathrm{C}$ to $100^{\circ} \mathrm{C}$, which then dropped at $150^{\circ} \mathrm{C}$ and decreased further at $200^{\circ} \mathrm{C}$. For $P / S^{2}$, intermediate temperatures generally had lower means; the $100^{\circ} \mathrm{C}$ case was significantly lower than the $20^{\circ} \mathrm{C}$ or $193^{\circ} \mathrm{C}$ cases. Our results for the ZDDP tribofilm are in agreement with other researchers in reporting that reduced modulus of a ZDDP tribofilm is relatively stable up to $150^{\circ} \mathrm{C}$ [37], but that hardness changes below $80^{\circ} \mathrm{C}$ [38]. In contrast, the mechanical properties of the $\mathrm{P}_{8888}$ and $\mathrm{ZDDP}+\mathrm{P}_{8888}$ tribofilms had no statistically significant change with increasing temperature, suggesting greater thermal stability. 

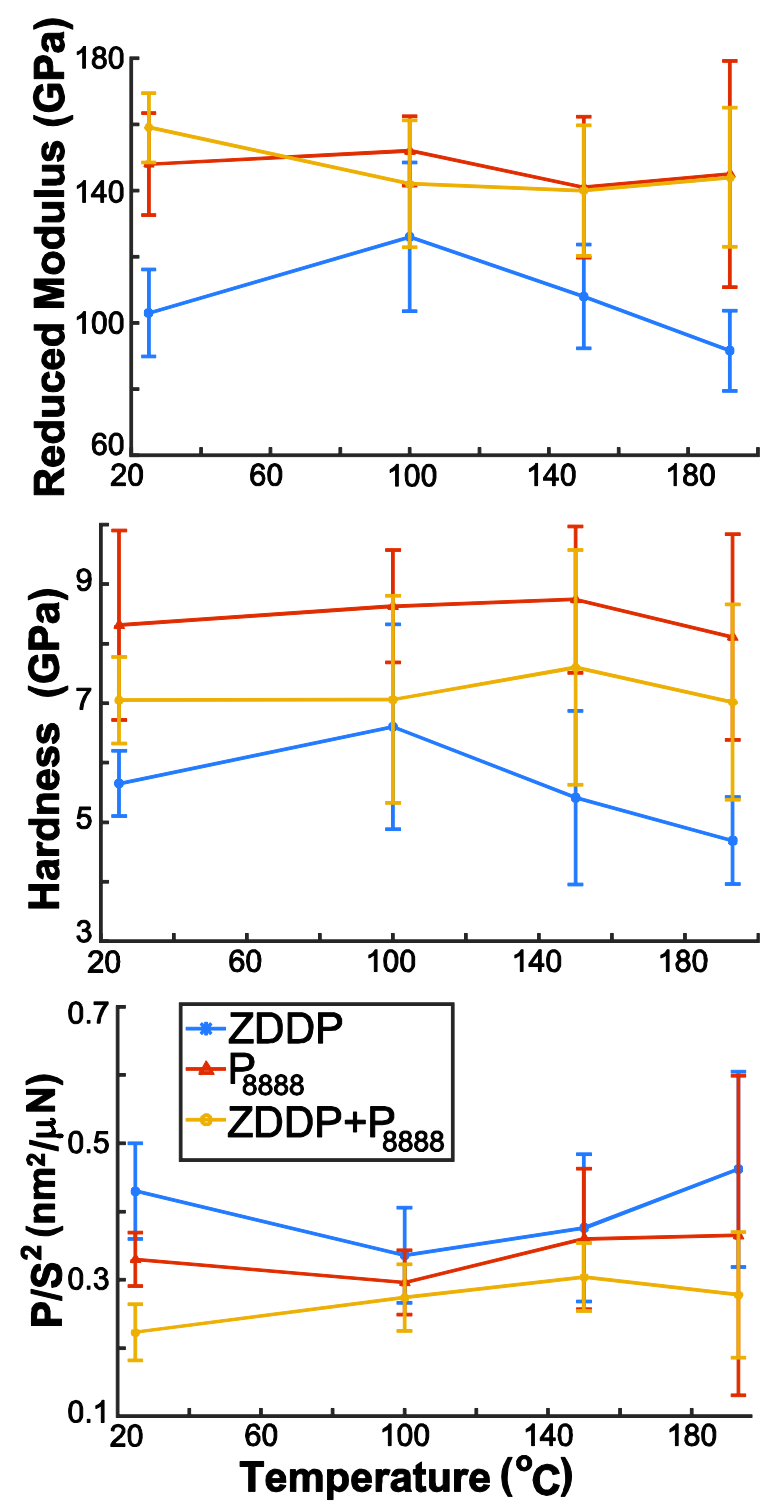

Figure 3. Measured properties across the range of temperatures tested. The IL tribofilm properties vary less than the ZDDP alone. Note the increase in uncertainty as temperature increases.

\subsection{Experimental Limitations}

With nanoindentation experimental uncertainties are inevitable. Since surface preparation was limited, roughness was highly variable; a contributing factor to non-homoscedasticity. Measurement errors arise due to drift, thickness inhomogeneity, substrate inhomogeneity, 
surface roughness, and contamination. Further challenges occur in high-temperature testing, as thermal expansion, thermal drift, and temperature control all contribute to error, particularly when testing above $150^{\circ} \mathrm{C}$. The stabilized temperature for $200^{\circ} \mathrm{C}$ (target) tests was $\sim 193^{\circ} \mathrm{C}$ due to radiative losses resulting from specimen geometry. Adequate power for statistical testing was achieved for each specimen, but only one to three wear tracks were tested for each lubricant chemistry. Previous studies indicate that ZDDP tribofilms have modulus $90 \pm 25 G P a$ to $125 \pm$ $14 G P a$ and hardness $4 \pm 1 G P a$ to $6 \pm 0.4 G P a$, depending on testing specifics $[18,23,26,40]$. Our results, $E_{r}=124.6 \pm 26.7 G P a$ and $H=5.1 \pm 1.4 G P a$, agree well.

\section{Conclusions}

Tribofilms generated in seven lubricants containing ZDDP, oil-miscible alkylphosphate ILs, or ZDDP+IL combinations were tested using nanoindentation at both room and elevated temperatures. IL and ZDDP+IL tribofilms exhibited greater thermal stability of mechanical properties compared with the ZDDP tribofilm. Generally, higher tribofilm modulus is associated with superior friction and wear behavior. No statistically significant trend was observed for the tribofilm hardness. The resistance-to-plastic-deformation $\left(P / S^{2}\right)$, showed strong correlation with tribological performance, but in an opposite trend as reported for bulk materials or coatings in literature: smaller $P / S^{2}$ corresponded to lower friction and wear. For bulk material or coated material, a higher $P / S^{2}$ ratio is associated with greater resistance to plastic deformation and thus lower wear. In contrast, a tribofilm is in-situ formed, sacrificial, and self-healing, and therefore a

lower $P / S^{2}$ ratio would lead to lower friction due to reduced resistance and elasticity dominated shear deformation, and lower wear since the film has greater elastic range with which to absorb energy upon surface asperity collisions and to reduce the damage to the substrate that it protects. 
Considered in totality, these results show systematic differences in material properties between tribofilms formed by different anti-wear additives, which indicate optimization directions for future lubricants development.

\section{Acknowledgements}

The authors thank A.E. Marquez Rossy from ORNL and Dr. S. Wang, Y. Meng, and D. Wu from University of Tennessee for training with nanoindentation, Dr. H. Luo from ORNL for synthesizing ILs, and Dr. B.L. Papke from Shell for providing GTL base oil and ZDDP. This research was sponsored by the Vehicle Technologies Office, Office of Energy Efficiency and Renewable Energy, US Department of Energy (DOE). This work was supported in part by the DOE, Office of Science, Office of Workforce Development for Teachers and Scientists (WDTS) under the Science Undergraduate Laboratory Internships program (Landauer) and Higher Education Research Experience (HERE) program (Barnhill).

Notice: This manuscript has been authored by UT-Battelle, LLC, under Contract No. DE-AC05O0OR22725 with the U.S. Department of Energy. The United States Government retains and the publisher, by accepting the article for publication, acknowledges that the United States Government retains a non-exclusive, paid-up, irrevocable, world-wide license to publish or reproduce the published form of this manuscript, or allow others to do so, for United States Government purposes.

\section{References}

[1] M.D. Bermudez, A.E. Jimenez, J. Sanes, F.J. Carrion, Ionic liquids as advanced lubricant fluids, Molecules, 14 (2009) 2888-2908. doi:10.3390/molecules14082888

[2] H. Spikes, The history and mechanisms of ZDDP, Tribol Lett, 17 (2004) 469-489. doi: 10.1023/B:TRIL.0000044495.26882.b5 
[3] C. Ye, W. Liu, Y. Chen, L. Yu, Room-temperature ionic liquids: a novel versatile lubricant, Chem Commun, 21 (2001) 2244-2245. doi: 10.1039/B106935G

[4] A. Matic, B. Scrosati, Ionic liquids for energy applications, MRS Bulletin, 38 (2013) 533537. doi: $10.1557 / \mathrm{mrs} .2013 .154$

[5] J. Qu, D.G. Bansal, B. Yu, J.Y. Howe, H.M. Luo, S. Dai, H. Li, P.J. Blau, B.G. Bunting, G. Mordukhovich, D.J. Smolenski, Antiwear performance and mechanism of an oil-miscible ionic liquid as a lubricant additive, ACS Appl Mater Inter, 4 (2012) 997-1002. doi:

$10.1021 / \mathrm{am} 201646 \mathrm{k}$

[6] B. Yu, D.G. Bansal, J. Qu, X.Q. Sun, H.M. Luo, S. Dai, P.J. Blau, B.G. Bunting, G. Mordukhovich, D.J. Smolenski, Oil-miscible and non-corrosive phosphonium-based ionic liquids as candidate lubricant additives, Wear, 289 (2012) 58-64. doi:

10.1016/j.wear.2012.04.015

[7] A. Somers, P. Howlett, D. MacFarlane, M. Forsyth, A Review of Ionic Liquid Lubricants, Lubricants, 1 (2013) 3-21. doi: 10.3390/lubricants1010003

[8] J. Qu, H.M. Luo, M.F. Chi, C. Ma, P.J. Blau, S. Dai, M.B. Viola, Comparison of an oilmiscible ionic liquid and ZDDP as a lubricant anti-wear additive, Tribol Int, 71 (2014) 88-97. doi: 10.1016/j.triboint.2013.11.010

[9] R. Gusain, R. Singh, K.L.N. Sivakumar, O.P. Khatri, Halogen-free imidazolium/ammoniumbis(salicylato)borate ionic liquids as high performance lubricant additives, Rsc Advances, 4 (2014) 1293-1301. doi: 10.1039/C3RA43052A

[10] Y. Zhou, J. Dyck, T.W. Graham, H.M. Luo, D.N. Leonard, J. Qu, Ionic liquids composed of phosphonium cations and organophosphate, carboxylate, and sulfonate anions as lubricant antiwear additives, Langmuir, 30 (2014) 13301-13311. doi: 10.1021/la5032366

[11] W.C. Barnhill, J. Qu, H.M. Luo, H.M. Meyer, 3rd, C. Ma, M. Chi, B.L. Papke, Phosphonium-organophosphate ionic liquids as lubricant additives: effects of cation structure on physicochemical and tribological characteristics, ACS Appl Mater Inter, 6 (2014) 22585-22593. doi: 10.1021/am506702u

[12] J. Qu, H. Luo, Ionic liquids containing symmetric quaternary phosphonium cations and phosphorus-containing anions, and their use as lubricant additives, (2014), in: U.S. Patent Application 14/184754.

[13] J. Qu, W.C. Barnhill, H. Luo, H.M. Meyer, D.N. Leonard, A.K. Landauer, B. Kheireddin, H. Gao, B.L. Papke, S. Dai, Synergistic Effects Between Phosphonium-Alkylphosphate Ionic Liquids and Zinc Dialkyldithiophosphate (ZDDP) as Lubricant Additives, Adv Mater, 27 (2015) 4767-74. doi: 10.1002/adma.201502037.

[14] W.C. Barnhill, H. Gao, B. Kheireddin, B.L. Papke, H. Luo, B.H. West, J. Qu, Tribological bench and engine dynamometer tests of a low viscosity SAE $0 \mathrm{~W}-16$ engine oil using a 
combination of ionic liquid and ZDDP as anti-wear additives, Frontiers in Mechanical Engineering, (2015) doi: 10.3389/fmech.2015.00012.

[15] F. Gustavsson, Triboactive Component Coatings: Tribological Testing and Microanalysis of Low-Friction Tribofilms, Department of Engineering Sciences, Uppsala Universitet, Digital Comprehensive Summaries of Uppsala Dissertations from the Faculty of Science and Technology 1011, 2013.

[16] J. Qu, P.J. Blau, S. Dai, H.M. Luo, H.M. Meyer III, Ionic Liquids as Novel Lubricants and Additives for Diesel Engine Applications, Tribol. Lett., 35 (2009) 181-189. doi: 10.1007/s11249009-9447-1

[17] I. Minami, Ionic liquids in tribology, Molecules, 14 (2009) 2286-2305. doi: 10.3390/molecules14062286

[18] R. Atkin, S.Z. El Abedin, R. Hayes, L.H.S. Gasparotto, N. Borisenko, F. Endres, AFM and STM Studies on the Surface Interaction of [BMP]TFSA and [EMIm]TFSA Ionic Liquids with Au(111), J Phys Chem C, 113 (2009) 13266-13272. doi: 10.1021/jp9026755

[19] J. Qu, H.M. Meyer, Z.-B. Cai, C. Ma, H. Luo, Characterization of ZDDP and ionic liquid tribofilms on non-metallic coatings providing insights of tribofilm formation mechanisms, Wear, 332 (2015) 1273-1285. doi:10.1016/j.wear.2015.01.076

[20] Z.-b. Cai, H.M. Meyer, C. Ma, M. Chi, H. Luo, J. Qu, Comparison of the tribological behavior of steel-steel and Si $3 \mathrm{~N}$ 4-steel contacts in lubricants with ZDDP or ionic liquid, Wear, 319 (2014) 172-183. doi:10.1016/j.wear.2014.08.002

[21] A. Banerji, A. Edrisy, V. Francis, A. Alpas, Effect of bio-fuel (E85) addition on lubricated sliding wear mechanisms of a eutectic Al-Si alloy, Wear, 311 (2014) 1-13.

doi:10.1016/j.wear.2013.12.011

[22] H.H. Elsentriecy, J. Qu, H.M. Luo, H.M. Meyer, C. Ma, M.F. Chi, Improving corrosion resistance of AZ31B magnesium alloy via a conversion coating produced by a protic ammonium-phosphate ionic liquid, Thin Solid Films, 568 (2014) 44-51. doi:

10.1016/j.tsf.2014.08.010

[23] J.P. Ye, M. Kano, Y. Yasuda, Evaluation of local mechanical properties in depth in MoDTC/ZDDP and ZDDP tribochemical reacted films using nanoindentation, Tribol. Lett., 13 (2002) 41-47. doi: 10.1023/A:1016559807453

[24] M.A. Nicholls, T. Do, P.R. Norton, G.M. Bancroft, M. Kasrai, T.W. Capehart, Y.T. Cheng, T. Perry, Chemical and mechanical properties of ZDDP antiwear films on steel and thermal spray coatings studied by XANES spectroscopy and nanoindentation techniques, Tribol Lett, 15 (2003) 241-248. doi: 10.1023/A:1024813203442

[25] G.M. Pharr, W.C. Oliver, Measurement of Thin-Film Mechanical-Properties Using Nanoindentation, MRS Bulletin, 17 (1992) 28-33. doi: 10.1557/S0883769400041634 
[26] K. Komvopoulos, V. Do, E.S. Yamaguchi, P.R. Ryason, Nanomechanical and nanotribological properties of an antiwear tribofilm produced from phosphorus-containing additives on boundary-lubricated steel surfaces, J Tribol-T Asme, 126 (2004) 775-780. doi: $10.1115 / 1.1792696$

[27] M. Aktary, M.T. McDermott, G.A. McAlpine, Morphology and nanomechanical properties of ZDDP antiwear films as a function of tribological contact time, Tribol Lett, 12 (2002) 155162. doi: 10.1023/A:1014755123184

[28] A.K. Bhattacharya, W.D. Nix, Analysis of Elastic and Plastic-Deformation Associated with Indentation Testing of Thin-Films on Substrates, Int J Solids Struct, 24 (1988) 1287-1298. doi: 10.1016/0020-7683(88)90091-1

[26] W.C. Oliver, G.M. Pharr, An Improved Technique for Determining Hardness and ElasticModulus Using Load and Displacement Sensing Indentation Experiments, J Mater Res, 7 (1992) 1564-1583. doi: 10.1557/JMR.1992.1564

[27] J. Hay, B. Crawford, Measuring substrate-independent modulus of thin films, J Mater Res, 26 (2011) 727-738. doi: 10.1557/jmr.2011.8

[28] R. Saha, W.D. Nix, Effects of the substrate on the determination of thin film mechanical properties by nanoindentation, Acta Mater, 50 (2002) 23-38. doi: 10.1016/S13596454(01)00328-7

[29] B. Zhou, B.C. Prorok, A new paradigm in thin film indentation, J Mater Res, 25 (2010) 1671-1678. doi: 10.1557/JMR.2010.0228

[29] W.C. Oliver, G.M. Pharr, An Improved Technique for Determining Hardness and ElasticModulus Using Load and Displacement Sensing Indentation Experiments, J Mater Res, 7 (1992) 1564-1583. doi: 10.1557/JMR.1992.1564

[30] J. Hay, B. Crawford, Measuring substrate-independent modulus of thin films, J Mater Res, 26 (2011) 727-738. doi: 10.1557/jmr.2011.8

[31] R. Saha, W.D. Nix, Effects of the substrate on the determination of thin film mechanical properties by nanoindentation, Acta Mater, 50 (2002) 23-38. doi: 10.1016/S13596454(01)00328-7

[32] B. Zhou, B.C. Prorok, A new paradigm in thin film indentation, J Mater Res, 25 (2010) 1671-1678. doi: 10.1557/JMR.2010.0228

[33] T.F. Page, G.M. Pharr, J.C. Hay, W.C. Oliver, B.N. Lucas, E. Herbert, L. Riester, Nanoindentation characterisation of coated systems: P: S2-a new approach using the continuous stiffness technique, MRS Proc, Cambridge Univ Press, pp. 53. doi: 10.1557/PROC-522-53

[34] D.L. Joslin, W.C. Oliver, A New Method for Analyzing Data from Continuous DepthSensing Microindentation Tests, J Mater Res, 5 (1990) 123-126. doi: 10.1557/JMR.1990.0123 
[35] J. Greenwood, J. Williamson, Contact of nominally flat surfaces, Proceedings of the Royal Society of London A: Mathematical, Physical and Engineering Sciences, The Royal Society, 1966, pp. 300-319. doi: 10.1098/rspa.1966.0242

[36] A. Leyland, A. Matthews, On the significance of the H/E ratio in wear control: a nanocomposite coating approach to optimised tribological behaviour, Wear, 246 (2000) 1-11. doi:10.1016/S0043-1648(00)00488-9

[37] G. Pereira, D. Munoz-Paniagua, A. Lachenwitzer, M. Kasrai, P.R. Norton, T.W. Capehart, T.A. Perry, Y.T. Cheng, A variable temperature mechanical analysis of ZDDP-derived antiwear films formed on 52100 steel, Wear, 262 (2007) 461-470. doi: 10.1016/j.wear.2006.06.016

[38] K. Demmou, S. Bec, J.L. Loubet, J.M. Martin, Temperature effects on mechanical properties of zinc dithiophosphate tribofilms, Tribol Int, 39 (2006) 1558-1563. doi: 10.1016/j.triboint.2006.01.025

[39] J. Sweeney, G.B. Webber, M.W. Rutland, R. Atkin, Effect of ion structure on nanoscale friction in protic ionic liquids, Phys Chem Chem Phys, 16 (2014) 16651-16658. doi: 10.1039/C4CP02320J

[40] S. Bhattacharya, A.T. Alpas, Role of sliding-induced tribofilms on fracture of particles in aluminium-silicon alloys, Wear, 301 (2013) 707-716. doi: 10.1016/j.wear.2013.01.081 